\title{
UCRL-CONF-220919
}

LAWRENCE LIVERMORE N A T IO N A L LABORATORY

\section{Axisymmetric Tandem Mirror Magnetic Fusion Energy Power Plant with Thick Liquid-Walls}

R. W. Moir, T. D. Rognlien

April 27, 2006

17th Topical Meeting on the Technology of Fusion Energy Albuquerque, NM, United States November 13, 2006 through November 15, 2006 
This document was prepared as an account of work sponsored by an agency of the United States Government. Neither the United States Government nor the University of California nor any of their employees, makes any warranty, express or implied, or assumes any legal liability or responsibility for the accuracy, completeness, or usefulness of any information, apparatus, product, or process disclosed, or represents that its use would not infringe privately owned rights. Reference herein to any specific commercial product, process, or service by trade name, trademark, manufacturer, or otherwise, does not necessarily constitute or imply its endorsement, recommendation, or favoring by the United States Government or the University of California. The views and opinions of authors expressed herein do not necessarily state or reflect those of the United States Government or the University of California, and shall not be used for advertising or product endorsement purposes. 


\title{
Axisymmetric tandem mirror magnetic fusion energy power plant with thick liquid-walls*
}

\author{
R. W. Moir and T. D. Rognlien \\ Lawrence Livermore National Laboratory, Livermore, CA \\ March 14, 2006
}

\begin{abstract}
A fusion power plant is described that utilizes a new version of the tandem mirror device including spinning liquid walls. The magnetic configuration is evaluated with an axisymmetric equilibrium code predicting an average beta of $60 \%$. The geometry allows a flowing molten salt, (flibe- $\left.\mathrm{Li}_{2} \mathrm{BeF}_{4}\right)$, which protects the walls and structures from damage arising from neutrons and plasma particles. The free surface between the liquid and the burning plasma is heated by bremsstrahlung radiation, line radiation, and by neutrons. The temperature of the free surface of the liquid is calculated, and then the evaporation rate is estimated from vapor-pressure data. The allowed impurity concentration in the burning plasma is taken as $1 \%$ fluorine, which gives a $17 \%$ reduction in the fusion power owing to $\mathrm{D} / \mathrm{T}$ fuel dilution, with $\mathrm{F}$ line-radiation causing minor power degradation. The end leakage power density of $0.6 \mathrm{MW} / \mathrm{m}^{2}$ is readily handled by liquid jets. The tritium breeding is adequate with natural lithium. A number of problem areas are identified that need further study to make the design more selfconsistent and workable; however, the simple geometry and the use of liquid walls promise the cost of power competitive with that from fission and coal.
\end{abstract}

\section{Introduction and background}

This paper summarizes a vision for a power plant that applies liquid walls to the kinetic-stabilized tandem mirror (K-S, TM) plasma confinement

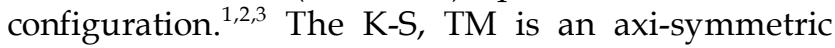
simplification of the complex, expensive version of tandem mirror that used highly non-axi-symmetric Yin-Yang coils in the end cells. For the remainder of the paper, we use the term tandem mirror to mean the axi-symmetric, kinetic-stabilized tandem mirror. Conventional structures for the region surrounding the fusing plasma appears feasible, but use of thick liquid ( 10 neutron mean free paths) facing the plasma and protecting solid structures holds the promise of lower cost of power and lower material development costs owing to substantial reduction of neutron damage by the liquid walls. ${ }^{4}$
The components of the design and organization of this paper follows:

- the configuration is based on MHD equilibrium calculations

- core plasma and other related parameters are given

- liquid wall flows are described; the surface temperatures are calculated (based on incident power on the liquid surface and interior heating)

- evaporation rates from the liquid surfaces that depend only on surface temperature are calculated

- the interface edge plasma is modeled and estimates are made of allowed evaporation based on core plasma impurity contamination

- tritium breeding is discussed

Common sense would suggest evaporation from the liquid walls would likely contaminate the fusing plasma and put out the fusion "burn". This may not be the case as it was long ago recognized that the halo or edge plasma surrounding the burning plasma can act as a pump by ionizing the evaporating liquid and transporting this ionized gas back to the liquid wall or axially to end tanks for pumping ${ }^{5}$. The choke coil with a $26 \mathrm{~T}$ field tends to retard this end leakage pumping.

We consider low conductivity molten salts liquids. The usual molten salt is flibe $\left(\mathrm{Li}_{2} \mathrm{BeF}_{4}\right)$, but past studies show the evaporation limits require temperatures near or below the melt temperature of $460{ }^{\circ} \mathrm{C}$ for this minimum viscosity mixture of $\mathrm{LiF}$ and $\mathrm{BeF}_{2}$. For $\mathrm{LiBeF}_{3}$ the melting point is $360^{\circ} \mathrm{C}$. Adding $\mathrm{NaF}$ to flibe produces flinabe $\left(\mathrm{NaF}+\mathrm{LiF}+\mathrm{BeF}_{2}=\mathrm{LiNaBeF}_{4}\right)$, whose melt temperature is reduced to $305^{\circ} \mathrm{C}^{6}$. The behavior of flinabe is so close to that of flibe that we will call it flibe throughout the paper. If the temperature is required to be low we may mean the reformulated version, called flinabe. As will be shown later, our design calls for the flibe to be injected at a temperature of $440{ }^{\circ} \mathrm{C}$. Avoiding freeze up in the heat exchanger will require care and formulation of flibe as mentioned above to obtain the minimum melt-temperature material. There are many aspects 
of the design that need further work. These are discussed throughout the report. conventional components of the plant that convert heat to electricity.

Later, more complete designs will allow cost estimates. In particular, we do not dwell on the
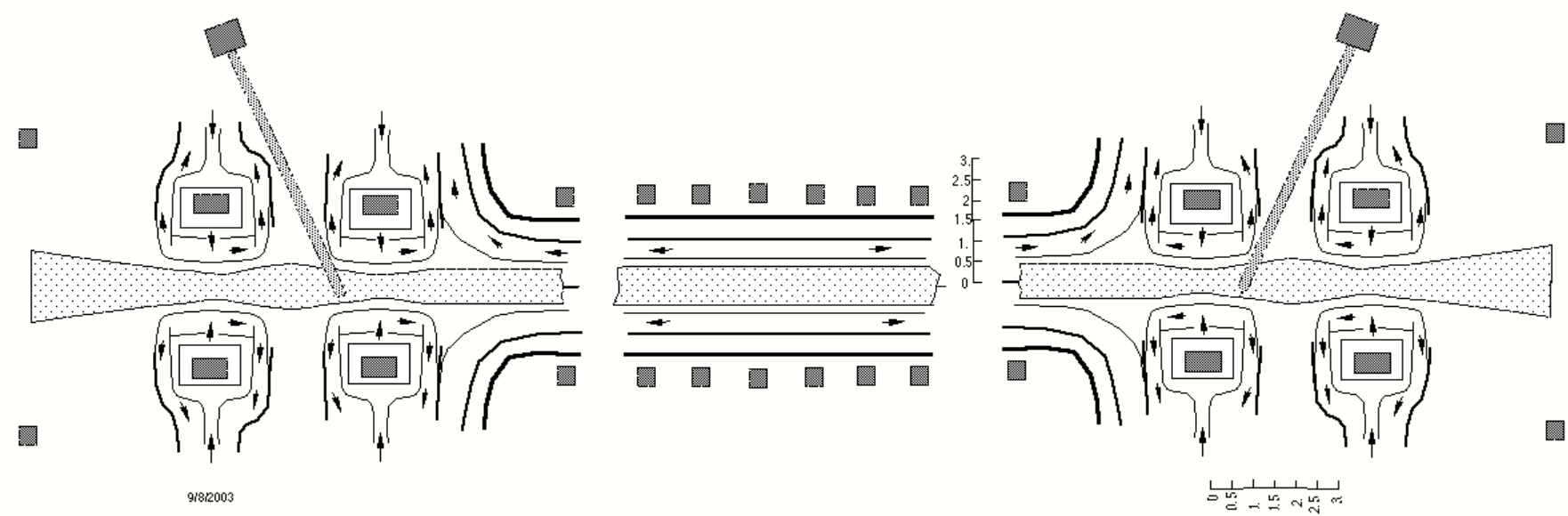

Fig. 1. The tandem mirror configuration with flowing liquid walls mostly in the azimuthal direction. The liquid flow is kept to the outside by centrifugal force.

\section{Configuration-equilibria}

The tandem mirror reactor configuration shown in Fig. 1 was assessed by the FLORA MHD stability code $^{7}$ and with codes written using the Mathematica ${ }^{\circledR}$ platform. The distance from the outer edge of the $0.42 \mathrm{~m}$ radius plasma to the flibe "wall" is taken to be $0.18 \mathrm{~m}$ and $0.75 \mathrm{~m}$ of flibe to the 30 $\mathrm{mm}$ thick steel wall followed by another $0.5 \mathrm{~m}$ of slowly flowing flibe. The main parameters are summarized in Table 1.

\section{Plasma parameters}

The example will be based on a related tandem mirror design called Mini-Mars ${ }^{8}$. The K-S TM version of the Minimars model has a plasma pressure radial profile giving a volume-averaged ratio of plasma to magnetic pressures $(\beta)$ of $60 \%$. The vacuum field is $3 \mathrm{~T}$ on axis. Based on prior work on the Field Reversed Configuration (FRC) ${ }^{9}$ and spheromak $^{10}$, we can scale to get a first approximation of some of the parameters as shown in Table 1. There is no reason to think this set of parameters is anywhere near optimum but rather will illustrate the features of a self-consistent design. For example, the power level of only 600 MWe is low by nuclear power plant trends by a factor of a few, and the neutron wall load of $2.7 \mathrm{MW} / \mathrm{m}^{2}$ is also low.

\section{Radiation model}

The assumed values for radiation used here are given in Table 1. At an electron temperature $(\mathrm{Te} \approx \mathrm{Ti})$ of $30 \mathrm{keV}$, impurities from flibe will be mostly in the highest charge state and, therefore, will produce modest line radiation. However, near the lower temperature edge-region, there will be increased line radiation.

The radiation from the core will consist of $\sim 85 \%$ bremsstrahlung radiation and $\sim 15 \%$ line radiation (see Fig. 4.10.1 of Ref.11). For an impurity fraction, $\mathrm{f}$, of 0.01 , the radiation fraction of fluorine is 0.0286 times the fusion power or 0.143 time the alpha power. This would amount to $34.3 \mathrm{MW}(85 \%$ or 29.2 MW of bremsstrahlung and $15 \%$ or $5.1 \mathrm{MW}$ of line radiation from the core).

Table 1 Typical power plant parameters.

\begin{tabular}{|l|l|}
\hline Liquid wall radius, $\mathrm{m}$ & 0.6 \\
\hline Plasma radius, $\mathrm{m}$ & 0.42 \\
\hline Center cell length, $\mathrm{m}$ & 95 \\
\hline Plasma volume, $\mathrm{m}^{3}$ & 53 \\
\hline Plasma area, $\mathrm{m}^{2}$ & 250 \\
\hline Liquid area, $\mathrm{m}^{2}$ & 360 \\
\hline Average ion temperature, $\mathrm{keV}$ & 30 \\
\hline Average ion density, $10^{20} \mathrm{~m}^{-3}$ & 2.2 \\
\hline Peak ion density, $10^{20} \mathrm{~m}^{-3}$ & 3.7 \\
\hline $\mathrm{Z}_{\text {eff }}$ & 1.72 \\
\hline $\mathrm{s}=$ plasma radius $/$ & 40 \\
\hline
\end{tabular}




\begin{tabular}{|l|l|}
\hline average larmor radius & \\
\hline Volume-averaged beta & 0.6 \\
\hline Magnetic field, T & 3.0 \\
\hline Mirror field, T & 26 \\
\hline Neutron wall load, MW/m² @ 0.6 m & 2.7 \\
\hline Surface heat load, MW/m ${ }^{2}$ & 0.11 \\
\hline Neutron power, MW & 960 \\
\hline Bremsstrahlung radiation power & $29 \mathrm{MW}$ \\
& $0.081 \mathrm{MW} / \mathrm{m}^{2}$ \\
\hline Line radiation, core & $5.1 \mathrm{MW}$ \\
& $0.014 \mathrm{MW} / \mathrm{m}^{2}$ \\
\hline Line radiation, edge & $4.6 \mathrm{MW}$ \\
& $0.013 \mathrm{MW} / \mathrm{m}^{2}$ \\
\hline Power to divertor, MW & 230 \\
$240+30-29.2-5.1-4.6=231$ & \\
\hline Input power, MW & $30 @ \mathrm{Q}=40$ \\
\hline Fusion power, MW & 1200 \\
\hline Net electric power, MWe & $\sim 600$ \\
\hline
\end{tabular}

For the UEDGE simulations of the edge plasma, the line radiation from fluorine in the scrape-off layer (SOL) is $1.9 \%$ of the alpha power, or $4.6 \mathrm{MW}$ when the fluorine level at the core boundary is $1 \%$ of the D-T density at the core/edge interface (taken to be $7.3 \times 10^{19} \mathrm{~m}^{-3}$ ). If the fluorine concentration remains constant in the core at $1 \%$, the fusion power is reduced by $17 \%$ owing to fuel dilution.

\section{Power plant considerations}

The power flows are based on prior studies [13]. We assume $1200 \mathrm{MW}$ of fusion power. Of this, $960 \mathrm{MW}$ is in the form of $14 \mathrm{MeV}$ neutrons. Nuclear reactions in the flibe blanket multiply this by $1.25^{12}$, giving $1200 \mathrm{MW}$ thermal power in the blanket. To this we add $240 \mathrm{MW}$ from alpha energy and $30 \mathrm{MW}$ of injected auxiliary power, all of which is absorbed by the flowing fluid either in the walls or in the divertor. We assume after startup the central plasma is ignited, i.e., alpha slowing down heats incoming cold D-T fuel. However, there is a power to sustain the end cells and the stabilizing beams. We assume a case with $Q=P_{\text {fusion }} / P_{\text {injection }}=40$, so $P_{\text {injection }}=30 \mathrm{MW}$. The total power going into the flowing fluid is 1470 MW.

\section{MW nuclear power in the blanket 240 MW alpha power $30 \mathrm{MW}$ injection power \\ $1470 \mathrm{MW}$ total}

The mass flow rate of the flibe to the power conversion plant, assuming a $50 \mathrm{~K}$ temperature drop across the heat exchanger, is

$$
\dot{m}=\frac{P}{C \cdot \Delta T}=\frac{1470 \mathrm{MW}}{2380 \mathrm{~J} / \mathrm{kgK} \cdot 50 \mathrm{~K}}=12,400 \mathrm{~kg} / \mathrm{s}
$$

Here the volumetric flow rate is $6.5 \mathrm{~m}^{3} / \mathrm{s}$.

The flow rate in the divertor jets and the liquid in the back of the blanket are comparatively small. The inlet temperature is taken to be $440{ }^{\circ} \mathrm{C}$ and the bulk or outlet temperature is $490{ }^{\circ} \mathrm{C}$.

\section{Liquid wall design}

The liquid wall, sketched in Fig. 2, flows with an injected azimuthal speed of $10 \mathrm{~m} / \mathrm{s}$ to keep the liquid on the outer wall by centrifugal force, as shown by K. Gulec in related prior studies ${ }^{13}$. He shows stable rotational flows for $a=v^{2} / r>3 g^{\prime} s$, where $\mathrm{a}$ is the rotational acceleration and $\mathrm{g}$ is the acceleration of gravity, $9.8 \mathrm{~m} / \mathrm{s}^{2}$. If the flow were like a rigid rotor with a shear slip condition at the back wall at $1.35 \mathrm{~m}$, then the acceleration at the back would be $10^{2} / 1.35=67 \mathrm{~m} / \mathrm{s}^{2}$ and at the front would be $4.4^{2} / 0.6=33 \mathrm{~m} / \mathrm{s}^{2}$, which satisfies our criterion of at least $3 \mathrm{~g}^{\prime} \mathrm{s}$ of outward centrifugal acceleration. Bardet, Supiot, Peterson and Savas ${ }^{14}$ have produced this flow pattern with an inner radius of $0.13 \mathrm{~m}$ compared to our design of $0.6 \mathrm{~m}$.

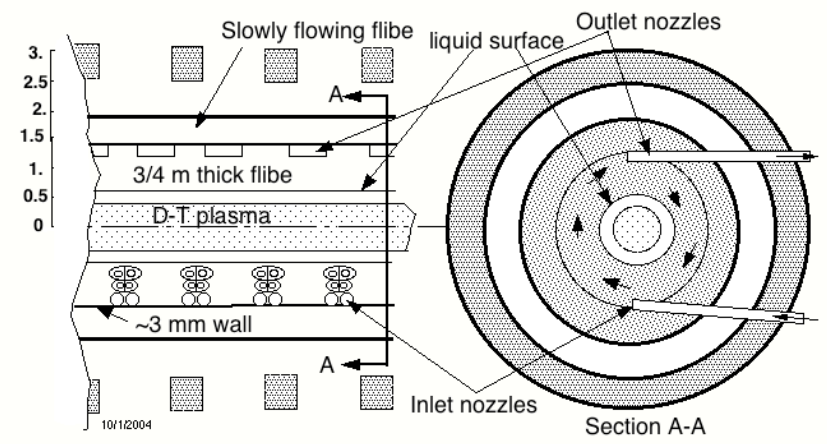

Fig. 2. Center cell liquid flows.

The bulk of the liquid is heated mostly by neutrons. The line radiation from the core interior, and the edge plasma and bremsstrahlung radiation from the core are absorbed near the surface. We determine the surface temperature in order to calculate the evaporation rate. We assume there are no droplets or splash contamination, nor is there sputtering enhancement of the evaporation.

The vapor pressure and evaporation rates are calculated from the following equations and plotted in Fig. 3:

$P(P a)=e^{(A-B / T)}$ 
$J=\frac{n \bar{\nabla}}{4}=\frac{p}{(2 \pi m k T)^{0.5}}=C T^{-0.5} e^{(A-B / T)}$

Here, $\quad A=26.59, \quad B=25,390$ and $C=(2 \pi m k)^{-}$ $0.5=3.828 \times 10^{23}$ for $\mathrm{BeF}_{2}$ evaporation. The flibe vapor pressure used is $\log _{10} P_{\text {torr }}=9.424-11026.208 / T(K)^{15,16}$ and is converted to Pascals by multiplying by 133.3. This latest estimate of evaporation rate is about a factor of three lower than previous estimates in the $500{ }^{\circ} \mathrm{C}$ region as can be seen in Fig. 3. It is about the same in the region of $1000{ }^{\circ} \mathrm{C}$. The equilibrium vapor density over a liquid is given in Fig. 4.

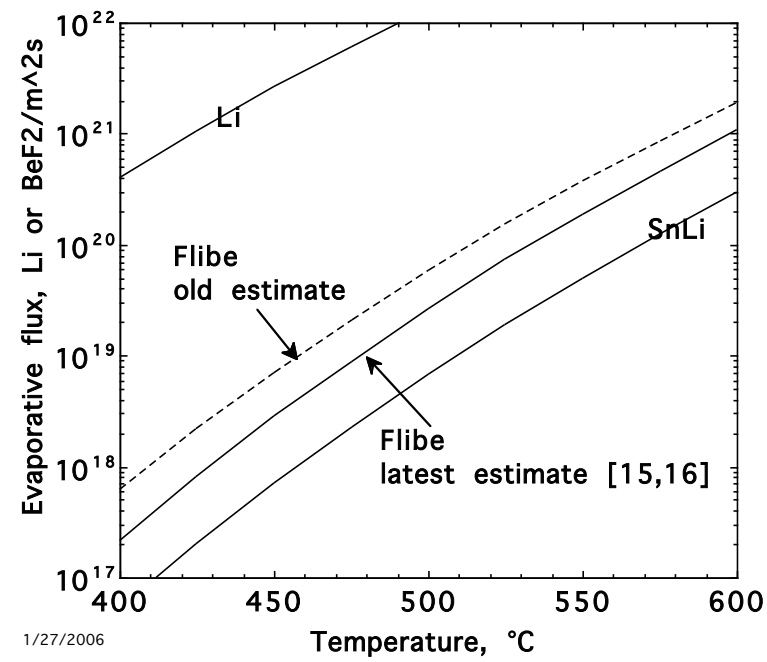

Fig. 3. Evaporation rates into vacuum for candidate liquids.

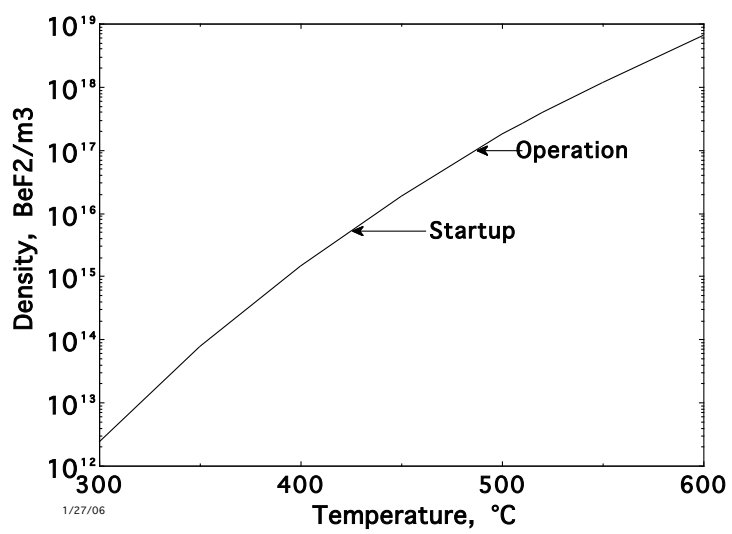

Fig. 4. Vapor density at equilibrium

The high Reynolds number (highly turbulent) flowing liquid with a free surface has eddies at the surface causing the surface to undulate. The transverse motion at and near the surface causes mass transport and, therefore, enhanced heat transfer beyond classical conduction. The surface heat transfer equation applicable is:

$$
\frac{P}{A}=h\left(T_{\text {bulk }}-T_{\text {surface }}\right)=h \Delta T_{\text {film }}
$$

The value of film temperature drop and $h$ are obtained in two ways. The first way is to use the " $k$ $\varepsilon^{\prime \prime}$ model $^{17,18}$ where we obtain an estimate of the heat transfer coefficient, $h$, of $13,000 \mathrm{MW} / \mathrm{m}^{2} \mathrm{~s}^{19}$.

The second way to estimate the film drop is based on a simple large eddy analysis discussed more fully in Ref. 19. We assume the surface eddies or boils expose the surface over a distance of $s$ for a time $t$. For our example we take $s$ to be the liquid thickness of $0.75 \mathrm{~m}$ and $\mathrm{t}$ to be $0.5 \mathrm{~s}$. Then the film drop for surface heating can be calculated as:

$\Delta T=T_{\text {surface }}-T_{\text {bulk }}=\Delta T_{\text {film }}=2 \cdot \frac{P}{A} \sqrt{\frac{t}{\pi k \rho C}}$

From Table 1 we see the total line radiation is 0.027 $\mathrm{MW} / \mathrm{m}^{2}$.

$\Delta T_{\text {film }}=2 \cdot 0.027 \mathrm{MW} / \mathrm{m}^{2} \sqrt{\frac{0.5 \mathrm{~s}}{\pi 1.06 \mathrm{~W} / \mathrm{mK} \times 1900 \mathrm{~kg} / \mathrm{m}^{3} \times 2380 \mathrm{~J} / \mathrm{kgK}}}$ $=9.8 \mathrm{~K}$

Both neutrons and bremsstrahlung penetrate deeply compared to the thermal conduction distance, about $70 \mathrm{~mm}$ and $1 \mathrm{~mm}$, respectively. The film drop for deep penetration is:

$$
\begin{aligned}
\Delta T_{\text {film }} & =\frac{P}{A} \frac{t}{\rho C \lambda} \\
\Delta T_{\text {film }} & =0.081 \mathrm{MW} / \mathrm{m}^{2} \frac{0.5 \mathrm{~s}}{1900 \mathrm{~kg} / \mathrm{m}^{3} \times 2380 \mathrm{~J} / \mathrm{kgK} \times 0.001 \mathrm{~m}}=9.0 \mathrm{~K}
\end{aligned}
$$

for bremsstrahlung.

$\Delta T_{\text {film }}=2.7 \mathrm{MW} / \mathrm{m}^{2} \frac{0.5 \mathrm{~s}}{1900 \mathrm{~kg} / \mathrm{m}^{3} \times 2380 \mathrm{~J} / \mathrm{kgK} \times 0.07 \mathrm{~m}}=4.3 \mathrm{~K}$

for neutrons,

$\Delta T_{\text {film }}=9.8 \mathrm{~K}$ line radiation $+9.0 \mathrm{~K}$ bremsstrahlung+ $4.3 \mathrm{~K}$ neutrons $=23.1 \mathrm{~K}$

Based on a surface heat load P/A of $0.11 \mathrm{MW} / \mathrm{m}^{2}$ (see Table 1) and a heat transfer coefficient of 13,000 $\mathrm{W} / \mathrm{m}^{2} \mathrm{~K}$, we get a film temperature drop of $8.3 \mathrm{~K}$. To this we add the neutron heating of $4.3 \mathrm{~K}$ to get a film drop estimate of $12.6 \mathrm{~K}$. The large eddy analysis above gives an estimate of $23 \mathrm{~K}$. The two methods of calculating film temperature give some idea of the uncertainty, which is at least a factor of two in film temperature drop. Surface mass transport measurements, for example on the UC Berkeley vortex of Ref. 14, can further quantify the relevant heat transfer properties for a more accurate prediction of $\Delta \mathrm{T}_{\text {film }}$ and therefore surface 
temperature. That is, statistical measurements could be made of the eddy size, s, and eddy surface speed and therefore, $t$, above.

Injection of vortex pairs as shown in Fig. 2 that are expected to propagate to the surface should enhance surface heat transfer coefficient, $\mathrm{h}$.

The surface temperature varies between the bulk temperature of $490{ }^{\circ} \mathrm{C}$ and $490+13$ or $+23{ }^{\circ} \mathrm{C}$. The surface temperature range of $503-513{ }^{\circ} \mathrm{C}$, shown in Tables 2, is used to bracket the calculated evaporation rates.

Table 2

Summary of temperatures for liquid walls

\begin{tabular}{|l|l|l|}
\hline $\mathrm{h}, \mathrm{MW} / \mathrm{m}^{2} \mathrm{~s}$ & 13,000 & 6,300 \\
\hline$\Delta \mathrm{T}_{\text {film }}{ }^{\circ} \mathrm{C}$ & 13 & 23 \\
\hline $\mathrm{T}_{\text {surface }}{ }^{\circ} \mathrm{C}$ & 503 & 513 \\
\hline $\begin{array}{l}\text { T-allowed from } \\
\text { impurity influx } \\
\text { analysis, }\end{array}$ & 502 to 516 \\
\hline
\end{tabular}

The average evaporative flux from the wall for flibe at a surface temperature of $503{ }^{\circ} \mathrm{C}$ is $3.0 \times 10^{19} \mathrm{~m}^{-2} \mathrm{~s}^{-1}$ and for $513{ }^{\circ} \mathrm{C}$ is $4.5 \times \quad \mathrm{m}^{-2} \mathrm{~s}^{-1}$ from Fig. 3. The inlet temperature is $440{ }^{\circ} \mathrm{C}$. The bulk temperature is $490{ }^{\circ} \mathrm{C}$. The amount of atomic impurity flux (discussed in the next section) that results in $1 \%$ impurity fluorine $(\mathrm{F})$ is $\sim 3-5 \times 10^{19} \mathrm{~F} \mathrm{~m}^{-2} \mathrm{~s}^{-1}$ from Fig. 11. If we assume that the flux of $F$ atoms directed toward the core plasma is the same as the molecular flux from the wall, the more recent "Flibe-latest estimate" curve in Fig. 3 predicts a surfacetemperature limit for the wall in the range 502$516{ }^{\circ} \mathrm{C}$. Rather, we assume that $50 \%$ of the $\mathrm{F}$ atoms produced by the dissociation of $\mathrm{BeF}_{2}$ near the liquid wall return to the wall because of the random direction of the velocity acquired from the dissociation process. Determining the precise fraction of dissociated $\mathrm{F}$ atoms returning directly to the wall requires more detailed modeling and if we instead assume all of the $\mathrm{F}$ atoms move toward the core, the allowable surface-temperature decreases by about $14{ }^{\circ} \mathrm{C}$.
The liquid wall can take a neutron wall load of much higher than $2.7 \mathrm{MW} / \mathrm{m}^{2}$ but the radiation heat load of $0.11 \mathrm{MW} / \mathrm{m}^{2}$ is limited by the allowable evaporation rate. If ways to improve the exhausting of vapor impurities by the edge plasma are found, the power density could be increased.

\section{End cell design}

The end cell magnets can be protected by liquids as shown in Fig. 5. A number of design issues are important, such as drip free inlet and outlet nozzles and access for neutral beams and pellets for fueling of the center cell and for initial heating of the center cell plasma.

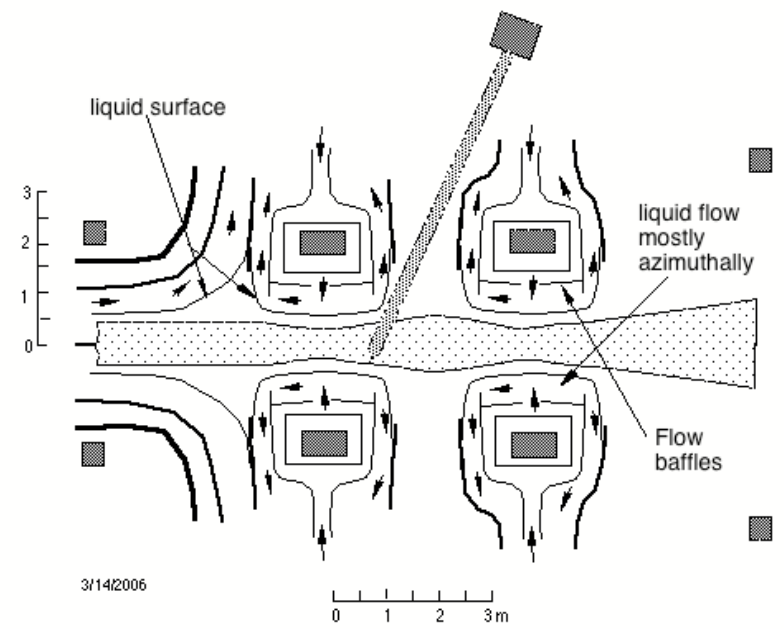

Fig. 5. End cell simplified.

\section{Divertor design}

The leaking edge plasma (radial transport and then axial loss) flows along open field lines until it strikes the divertor liquid surface. This amounts to $230 \mathrm{MW}$ or $115 \mathrm{MW}$ to each end. If the radius of the end tanks is $8 \mathrm{~m}$ then the power will be $0.6 \mathrm{MW} / \mathrm{m}^{2}$. The magnetic field at the end wall would be $8.3 \times 10^{-3} \mathrm{~T}$ (83 gauss). Note that the flowing plasma is composed of ionized $\mathrm{F}, \mathrm{Be}$ and $\mathrm{Li}$ as well as $\mathrm{D}, \mathrm{T}$ and He. To avoid corrosion, these ions must not strike a solid surface. Rather they must strike flowing liquid where $\mathrm{Li}_{2} \mathrm{BeF}_{4}$ is reconstituted. 


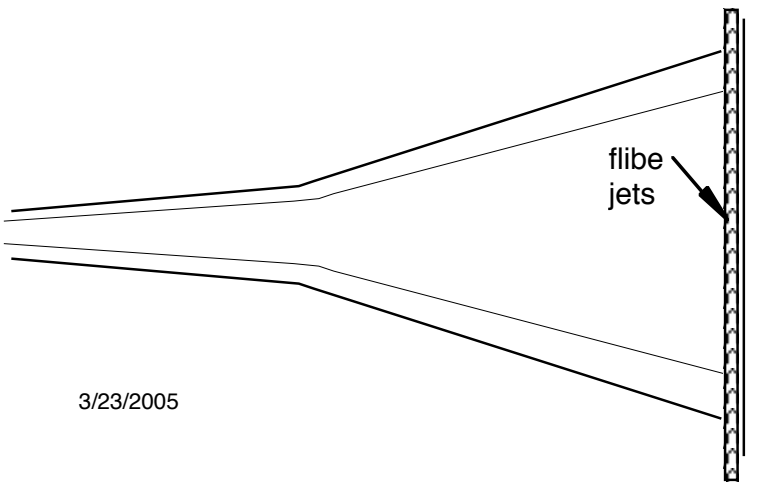

Fig. 6 End tank flibe jets shown to carry away end loss power.

The power density on the end tank is so low that a simple slab jet as shown in Fig. 6 might be able to carry away the heat with small enough evaporation.

Sputtering and evaporation set the temperature limit of the divertor surfaces. The latter limit involves the sheath superheat phenomenon, as studied for tokamaks ${ }^{20,21}$. Based on those studies, a rough evaporation-based limit for the present purposes is set by the condition that the evaporating impurity flux is approximately equal to the incoming hydrogen ion flux. This flux ratio is, $G=$ (impurity atom flux)/(hydrogen ion flux). When G >> 1, (exact limit depending on surface material, flow velocity, and plasma parameters), the sheath collapses and runaway overheating of the surface occurs.

The temperature of the surface of a slab can be calculated

$$
\begin{aligned}
& T=T_{i n}+2 \cdot \frac{P}{A} \sqrt{\frac{t}{\pi k \rho C}} \\
& \mathrm{t}=\mathrm{d} / \mathrm{v}
\end{aligned}
$$

$t$ is the time to travel across the end tank of diameter $\mathrm{d}$, of $16 \mathrm{~m}$, traveling with the liquid slab jet of speed $\mathrm{v}, \mathrm{k}$ is the thermal conductivity of flibe $1.06 \mathrm{Wm} / \mathrm{K}$, $\rho$ is the density, $1900 \mathrm{~kg} / \mathrm{m}^{3}, \mathrm{C}$ is heat capacity, 2380 $\mathrm{J} / \mathrm{kgK}$. For an inlet temperature, $\mathrm{T}_{\text {in }}$ of $425^{\circ} \mathrm{C}$ we get the peak temperature on the slab as it crosses the largest distance and the peak evaporation rate there, as plotted in Fig. 7 .

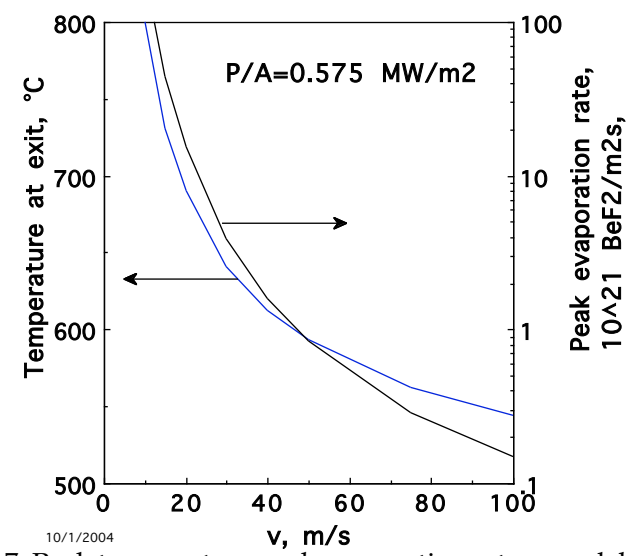

Fig. 7. Peak temperature and evaporation rate on a slab of flibe moving with speed $\mathrm{v}$.

To judge whether this evaporation rate is acceptable, we consider the end leakage. From Table 1 the ion density is $2.210^{20} / \mathrm{m}^{3}$. The plasma volume is $53 \mathrm{~m}^{3}$. If the product $n t=10^{20}$, then $\mathrm{t}=0.45 \mathrm{~s}$. The end leakage out each end is

$$
\frac{2.2 \times 10^{20} \mathrm{~m}^{-3} \cdot 53 \mathrm{~m}^{3}}{0.45 \mathrm{~s}}=2.6 \times 10^{22} / \mathrm{s}
$$

An $8 \mathrm{~m}$ radius end tank has an end wall area of 200 $\mathrm{m}^{2}$. The end flux of particles is $1.3 \times 10^{20} / \mathrm{m}^{2} \mathrm{~s}$. From Fig. 7 we see that the peak evaporation flux at a slab speed of $100 \mathrm{~m} / \mathrm{s}$ is $1.5 \times 10^{20} \mathrm{~F}_{2} / \mathrm{m}^{2} \mathrm{~s}$ or $3.0 \times 10^{20} \mathrm{~F} / \mathrm{m}^{2} \mathrm{~s}$ at a temperature of $540{ }^{\circ} \mathrm{C}$, giving $\mathrm{G}=3 / 1.3=2.3$. Obtaining a speed of $100 \mathrm{~m} / \mathrm{s}$ is challenging.

We can reduce the evaporation rate and the jet speed required by a number of design changes. By interleaving slab jets, the exposed distance can be cut almost in half. This reduces the peak evaporation rate by about a factor of ten. Another way is to use small diameter round jets $(<1 \mathrm{~mm}$ dia) that rotate, thus exposing more area [Ref 10]. This reduces the power flux by a factor of $\pi$ to $0.18 \mathrm{MW} / \mathrm{m}^{2}$. The jets can be made to break up into spinning droplets with 4 times the surface area as the frontal area for an average surface power density of $0.14 \mathrm{MW} / \mathrm{m}^{2}$, further enhancing their ability to remove heat at lower evaporation rates. 


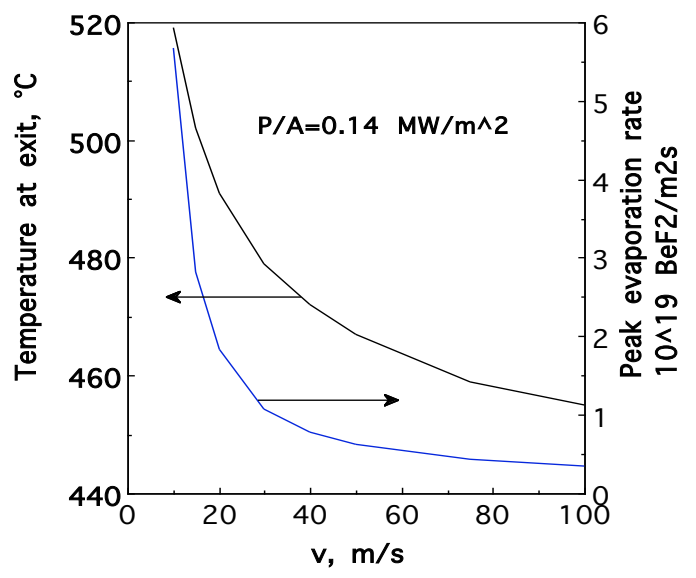

Fig. 8 Peak temperature and evaporation rate on spinning droplets of flibe moving with speed $\mathrm{v}$.

The peak evaporation rate gives $\mathrm{G}=1$ at a speed slightly over $10 \mathrm{~m} / \mathrm{s}$.

\section{Impurity contamination}

The halo or edge plasma, sometimes called the scrape-off layer (SOL), shields the core plasma from the impurities that evaporate from the liquid wall. Here we discuss the modeling of the SOL plasma and present results on the effectiveness of the shielding for the present configuration. The maximum flux of impurities that the SOL plasma can shield, as set by the acceptable core impurity level, then determines the allowable surface temperature of the liquid. The liquid surface is heated by a combination of bremsstrahlung and line radiation from the core and edge region (see Table 1).

We use the 2-D UEDGE transport code [23, 22] to calculate hydrogenic and impurity plasma profiles for a given set of radial transport diffusion coefficients.

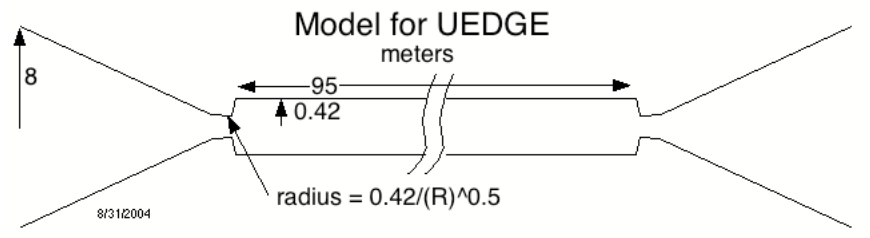

Fig. 9 Geometry and dimensions for the edge-plasma region modeled by UEDGE.

The model for the edge plasma considers the thin annular edge region as a long-thin plasma slab. The distance along the magnetic field is taken as the $95 \mathrm{~m}$ length of the central cell, and the radial width is taken as $0.2 \mathrm{~m}$ (approximating $0.18 \mathrm{~m}$ from Fig. 1) for the nominal case; a variation with a width to $0.1 \mathrm{~m}$ is also considered. The transition to the ends, where a strong magnetic field produces a mirror ratio of 8.7 , is modeled by reducing the parallel loss flux by the same 8.7 factor. This procedure corresponds to the expected reduction of axial confinement time in the collisional flow regime of the cool edge plasma [Ref 22]; here the ion loss-cone is filled by collisions, and the confining barrier potential is not operative. We assume that the region beyond the mirror can be designed to give low recycling of the hydrogen plasma, perhaps by drawing these field lines into a large dump tank. Thus, the hydrogenic recycling coefficient at the end of the simulation domain is assumed to be $R_{h}=0.1$. At the separatrix, the density of the hydrogenic species (a $50 / 50 \%$ mixture of deuterium and tritium $[D T\})$ is taken to be $1 / 3$ the volume-averaged value, or $7.3 \times 10^{19} \mathrm{~m}^{-3}$, and power into the SOL is taken as $230 \mathrm{MW}$ (or $0.92 \mathrm{MW} / \mathrm{m}^{2}$ ) divided equally between the ion and electron channels. Impurity line radial from the impurity species ( $F$ here) is included as an electron energy loss. The anomalous radial diffusion coefficients arising from plasma turbulence are $0.25 \mathrm{~m}^{2} / \mathrm{s}$ for all density species and $0.5 \mathrm{~m}^{2} / \mathrm{s}$ for electron and ion thermal energies. Because the radial turbulent plasma transport is very uncertain, we also consider a case with ten times these values. The profiles of plasma density and separate electron and ion temperatures are here referred to as selfconsistent within this transport model. Even with the variation of radial diffusion coefficients considered, there remains substantial uncertainty as to the true nature of the impurity transport in the tandem mirror edge plasmas, which could contain an inward convection process that would enhance the impurity contamination.

The calculated radial plasma profiles at the outer midplane are shown in Fig. 10. There is an initial rapid radial fall-off of the hydrogen density, but a broad plateau-like region exists once $T_{e}$ falls to low values. If the flux of $\mathrm{F}$ from the wall is omitted, the edge-plasma temperatures remain fairly high, $\mathrm{T}_{\mathrm{e}} \sim 100 \mathrm{eV}$ and $\mathrm{T}_{\mathrm{i}} \sim 400 \mathrm{eV}$, even out to the wall. The line radiation introduced by the evaporated $F$ causes $T_{e}$ to rapidly decay to small values away from the core/edge interface (see Fig. 10), and strong electron-ion collisional energy-coupling forces $T_{i}$ to decay as well. For the case shown in Fig. 10, the low $\mathrm{T}_{e}$ in the outer region allows neutral $\mathrm{F}$ to easily penetrate to about $0.05 \mathrm{~m}$ before it is strongly ionized. 


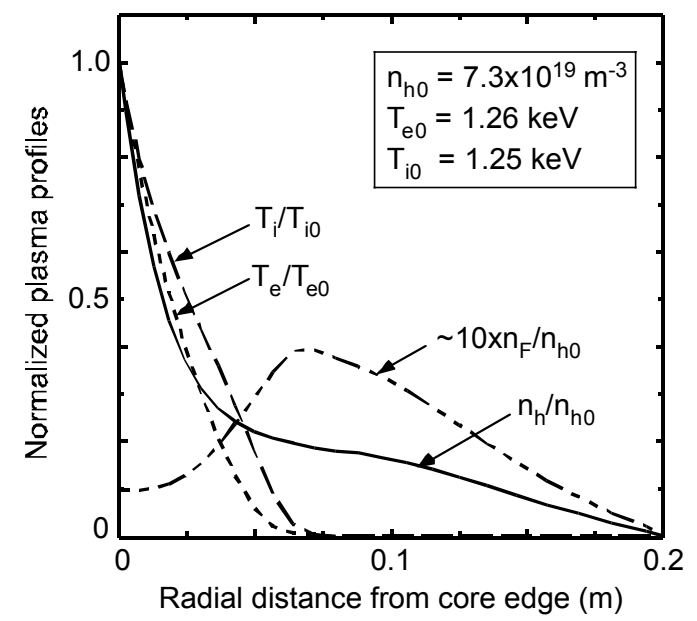

Fig. 10. Edge plasma radial profiles including hydrogen ion and fluorine densities and electron densities, and electron and ion temperatures for the base case slightly below the critical F flux of $\sim 3 \times 10^{19} \mathrm{~m}^{-2} \mathrm{~s}^{-1}$. The input power flux across left-hand core boundary is $0.92 \mathrm{MW} / \mathrm{m}^{2}$, and particle flux of fluorine from the wall at $\mathrm{r}=0.2 \mathrm{~m}$ is $2.9 \times 10^{19} \mathrm{~m}^{-2} \mathrm{~s}^{-1}$.

For these simulations, the impurity gas coming from the liquid wall is modeled as a uniform flux along the radial boundary at $\mathrm{r}=0.6 \mathrm{~m}$ (which is $20 \mathrm{~cm}$ beyond the nominal core-boundary) at a temperature of $1 \mathrm{eV}$. More details on the transport model and the sensitivity of results for various assumptions are given in Ref. [23]. The impurities have the same anomalous radial diffusion coefficients as the hydrogenic species. The impurity ions that return to the side wall and those reaching the divertor plate through axial flow are assumed to be mostly reabsorbed into the liquid with a small recycling coefficient of $R_{\text {imp }}=0.1$. Previous studies have shown that owing to its higher charge (and thus emissivity), fluorine is the most limiting impurity. So we limit our modeling to fluorine.

Three cases are considered in detail (including that shown in Fig. 10): (1), the base case with the liquid wall $20 \mathrm{~cm}$ from the "edge" of the core plasma with diffusion coefficients for density of $0.25 \mathrm{~m}^{2} / \mathrm{s}$ and 0.5 $\mathrm{m}^{2} / \mathrm{s}$ for energy (see Fig. 10); (2), ten times the diffusion coefficients for density and energy (due to a possible increase in turbulent modes); and (3), the base diffusion coefficients but with $1 / 2$ the radial width (here $10 \mathrm{~cm}$ ) to the wall. The results are plotted versus the impurity $(\mathrm{F})$ concentration and reach the core edge boundary as a function of the fluorine evaporative flux from the wall in Fig. 11. An acceptable level of $\mathrm{F}$ concentration is taken to be $1 \%$, since this level in the full core would yield a $17 \%$ fusion power loss at a constant electron density owing to DT fuel dilution.
The results of the 3 cases shown in Fig. 11 yield very similar values of the maximum acceptable $F$ gas flux producing a fluorine ion concentration of $1 \%$ at the core boundary; the range of such gas fluxes is $\sim 3-5 \times 10^{19} \mathrm{~m}^{-2} \mathrm{~s}^{1}$. The new flibe curve in Fig. 3 sets a surface temperature limit of about $\mathrm{T}=502$ to $513{ }^{\circ} \mathrm{C}$. There are many uncertainties in modeling this edge region and the impurity transport there, but the fact that the three different cases give very similar limits indicates a weak sensitivity to some of the details. Note that the apparent discontinuous behavior of the case with 10x diffusion in Fig. 11 is caused by a bifurcation in the solution as discussed in Ref. [23]; the region of negative slope is not carefully resolved here as it likely corresponds to unstable solutions. The bifurcation is normally associated with a thermal collapse of the edge plasma very near the wall. Auxiliary heating in this region may extend the allowable gas fluxes and thus wall temperature. Also, for the base case, most of the F ion loss is axial, whereas in the 10x diffusion case, most of the $\mathrm{F}$ ion loss is back to the radial wall (with self-sputtering ignored).

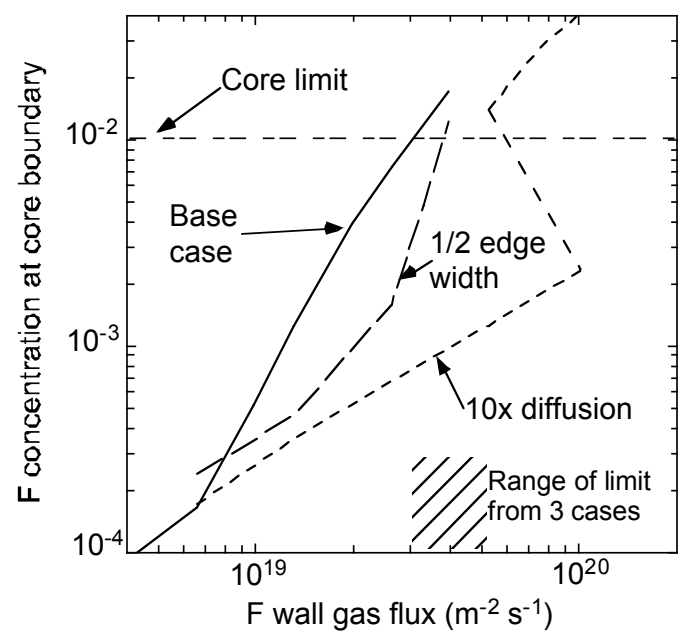

Fig. 11. Concentration of fluorine $\left(n_{i m p} / n_{e}\right)$ at the core boundary for increasing $\mathrm{F}$ gas fluxes corresponding to increased liquid wall surface temperature. The 3 cases shown are described in the text.

\section{Tritium breeding analysis}

The radial blanket consists of $0.75 \mathrm{~m}$ thick fastflowing liquid layer followed by a $\sim 3 \mathrm{~mm}$ thick steel wall and then $\sim 0.5 \mathrm{~m}$ thick slow-flowing liquid layer and an assumed $5 \%$ steel structure by volume. The infinite-medium tritium-breeding ratio (TBR) is 1.25 for flibe and 1.10 for flinabe ${ }^{12}$. There will be some neutrons lost to end leakage and some loss to structural steel. Our liquid is so thick that the 
infinite-medium case is appropriate, and adequate tritium-breeding ratio exceeding unity by an acceptable margin for self-sustained operation seems likely.

\section{Conclusions and discussion}

This study examines an axisymmetric tandem mirror fusion power plant with a flowing liquid wall. We are sufficiently encouraged by the results to recommend further work on the concept if the prospects of achieving adequate confinement look good. The advantages of the simpler reactor embodiment of the tandem mirror and the advantages of liquid walls are impressive. Evaporation from the walls, while high, is acceptable with some margin according to our analysis and criterion. The film-drop calculation used $0.11 \mathrm{MW} / \mathrm{m}^{2}$ surface heat load. Better estimates of surface temperature are needed. This requires better analysis and experiments on turbulent heat transfer at the free surface of turbulent liquid flows. The evaporation in the divertor from the 0.6 $\mathrm{MW} / \mathrm{m}^{2}$ power density seems manageable.

\section{Acknowledgments}

*Work performed under the auspice of the U.S. Department of Energy by University of California Lawrence Livermore National Laboratory under Contract W-7405-Eng-48. Support by Vallecitos Research Associates and Kyoto University, Institute of Advanced Energy is appreciated.

\section{References}

5. J. S. Foster, Jr., E. O. Lawrence, and E. J. Lofgren, "A high vacuum high speed ion pump," Rev. Sci. Instr. 24 (1953) 388-390.

6. R. E. Nygren, "Thermal modeling of the Sandia flinabe (LiF-BeF2-NaF) experiment," Fusion Science \& Technology 47 (2005) 549-553.

7. B. I. Cohen, R. P. Fries, and W. A. Newcomb, "Interchange, rotational, and ballooning stability of long-thin axisymmetric systems with finite-orbit effects," Phys. Fluids 29 (5) (1986) 1558-1577.

8. L. J. Perkins, B. G. Logan, R. B. Campbell, R. S. Devoto, D. T. Blackfield, and B. H. Johnston, "Plasma engineering for Minimars: a small commercial tandem mirror reactor with octopole plugs," Fusion Technology, 8 (1985), 689.

9. R. W. Moir, R. H. Bulmer, K. Gulec, P. Fogarty, B. Nelson, M. Ohnishi, M. Rensink, T. D. Rognlien, J. F. Santarius and D. K. Sze, "Thick liquid-walled field-reversed configurationmagnetic fusion power plant," Fusion Technology 39, 758-767 (2001).

10. R.W. Moir, R.H. Bulmer, T.K. Fowler, T.D. Rognlien, M.Z. Youssef, "Spheromak magnetic fusion power plant with thick liquid-walls," Fusion Science and Technology, 44 (2003) 317-326.

11. J. Wesson, Tokamaks, Clarendon Press, Oxford (1987).

12. L. El-Guebaly and the ARIES Team, "Views on neutronics and activation issues facing liquidprotected IFE chambers," Fusion Science $\mathcal{E}$ Technology, 47 (2004) 544-548.

13. M. A. Abdou et al. "On the exploration of innovative concepts for fusion chamber technology," UCLA-ENG-99-206 (1999) p 5-94 to 5-105. See also M. A. Abdou et al., Fusion Engineering and Design 54 (2001) 181-247.

14. P. M. Bardet, C. S. Debonnel, J. Freeman, G. Fukuda, B. Supiot, P. F. Peterson, "Dynamics of liquid-protected fusion chambers," Fusion Science \& Technology, 47 (2004) 626-632.

15. D. R. Olander, G. T. Fukuda, and C. F. Baes, Jr., "Equilibrium pressure over BeF2/LiF (Flibe) molten mixtures," Fusion Technology 41 (2002) 141.

16. M. R. Zaghloul, D, K. Sze and A. R. Raffray, "Thermo-physical properties and equilibrium vapor-composition of lithium fluoride-beryllium fluoride $\left(2 \mathrm{LiF} / \mathrm{BeF}_{2}\right)$ molten salt," Fusion Science and Technology 44 (2003) 344-350.

17. S. Smolentsev, UCLA, private communications, November 13, 2001.

18. S. Smolentsev, M. Abdou, N. Morley, A. Ying,

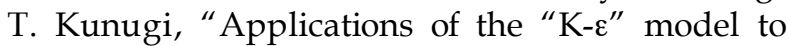
open channel flows in a magnetic field," Int. J. Engineering Science, 40/6, 693-711 (2002).

19. R. W. Moir, R. H. Bulmer, T. K. Fowler, T. D. Rognlien, M. Z. Youssef, "Thick liquid-walled spheromak magnetic fusion power plant," LLNL Report UCRL-ID-148021 Rev. 2 (2003).

20. J. N. Brooks and D. Naujoks, "Sheath superheat transmission due to redeposition of thermally emitted material," Phys. Plasmas 7 (2000) 2565.

21. D. Naujoks and J.N. Brooks, "Combined sheath and thermal analysis of overheated surfaces in fusion devices," J. Nucl. Mater., 290-293 (2001) 1123.

22. T. D. Rognlien and T.A. Cutler, "Transition from Pastukhov to collisional confinement in a magnetic and electrostatic well," Nucl. Fusion 20 (1980) 1003. 
23. T. D. Rognlien and M. E. Rensink, "Impurity transport in edge plasmas with application to liquid walls." Phys. Plasmas 9 (2002) 2120. 